\title{
Expectation and extraversion: Influencing the perceived rate of tone-silence sequences
}

\author{
STANLEY FELDSTEIN \\ University of Maryland Baltimore County, Baltimore, Maryland \\ CYNTHIA L. CROWN \\ Xavier University, Cincinnati, Ohio \\ and \\ JOSEPH JAFFE \\ College of Physicians and Surgeons, Columbia University, New York, New York
}

\begin{abstract}
It was hypothesized that expectation (instructional set) influences the perceived tempo of tone-silence sequences, and that this perception is also affected by the degree to which the perceivers are extraverted. Twenty-two university undergraduates were asked to judge the rates of 10 tone-silence sequences, which were transformations of actual speech samples. The subjects were divided into two groups, one of which was informed about the fact that the sequences were transformations, and the other of which was not told anything about the sequences. After completing their judgments about the sequences, the participants were asked to complete the Eysenck Extraversion scale. Contrary to the hypothesis, the analyses provided no evidence that the perceived rates of the informed participants were different from those of the uninformed participants, but they did indicate that (1) the perceived rates of the sequences were closely related to the tempos (words per minute) of the speech samples from which the sequences were derived, and (2) extraverts judged the rates of the sequences to be faster than did introverts. Implications for the "modular" theory of acoustic perception are discussed.
\end{abstract}

In the present study, we had two aims: (1) to determine whether instructional set differentially influences the perceived tempo of sequences of tones and silences; and (2) to examine the possibility that the perception of tempo is affected by the personality characteristic of extraversion. ${ }^{1}$

The impetus for the first aim came from two studies by Crown and Feldstein (1991), in which we were concerned with determining the minimal amount of information needed for the judgment of speech rate. In an extensive and elegant series of studies, Grosjean and Lane and their associates (e.g., Grosjean, 1977; Lane \& Grosjean, 1973; and Grosjean \& Lane, 1981, for a brief review) found that the perception of speech rate, and particularly of reading rate, is primarily a function of variations in articulation rate and in the frequencies and durations of pauses. They (Grosjean \& Lane, 1974, 1981) demonstrated that listeners, in their perception of reading rate, use and integrate these three components of speech. For

The authors are indebted to the Language Center and to the Academic Computing Center of the University of Maryland (Baltimore County) for making their facilities and time so readily available. They are also grateful to David Moore, who served as the experimenter in the study, and to Terri Harold, who edited the final draft of the paper. This paper was presented as a poster at the first meeting of the American Psychological Society (Alexandria, VA, June 1989). Requests for reprints should be sent to Stanley Feldstein, Department of Psychology, University of Maryland, Baltimore, MD 21228. the demonstration, versions of a passage were read aloud in which the pause durations and placements were experimentally varied (by tape splicing). The versions also contained full semantic and syntactic information. Thus Grosjean and Lane did not address the question of whether listeners could judge speech rate from samples that provide only minimum information.

The removal of semantic and syntactic information from speech samples would leave sequences of sounds and silences, although the sounds would still retain frequency and intensity information. Such information, however, has been shown to significantly influence the perception of speech rate (see, e.g., Bond, Feldstein, \& Simpson, 1988). Were frequency and intensity information then removed from the samples, the remaining sounds would vary only in duration. The "speech" samples would then be sequences of sounds of a single frequency and intensity but of varying durations, separated by silences of varying durations. These sequences would presumably convey the minimal amount of information available in speech. Crown and Feldstein (1991) reported that, after listening to sound-silence sequences derived from actual speech, judges were able to distinguish between slow and moderate rates but not between moderate and fast rates. The judges were told that the sound-silence sequences were derived from actual speech, and the results indicated that the average perceived rate of the sequences did not 
differ markedly from the average perceived rate of the original speech samples.

Liberman and Mattingly (1989), however, have argued that speech and nonspeech stimuli are processed by different internal "modules," which raises the question of whether the different "modules" also differentially process rate information. The finding of the Crown and Feldstein (1991) study argues against such differential processing of rate, but it raises another question about whether expectation plays a role in how speech and nonspeech stimuli are processed. In an effort to answer this question, in the present study we informed one group of judges that the sequences were derived from actual speech, but we did not inform the other group. We anticipated that the judges' belief that the sequences were derived from actual speech samples would generate an expectation that would influence their perception of the rate of the sequences. Our second aim was to examine the influence of extraversion on the perception of rate. Extraversion is one of the few personality characteristics that has been shown to directly affect both kinesic and, particularly, vocal behavior. Siegman (1987) has reviewed an impressive list of studies that have demonstrated the influence of extraversion on the pitch and loudness of the voice and on rate of speech. There is, in other words, considerable evidence (e.g., Feldstein \& Sloan, 1984; Scherer, 1978) that rapid, loud speech is a stereotype commonly attributed to extraverts. There is also evidence (Lippa, 1976) that extraverts move more quickly than introverts. That extraverts move and speak faster than introverts suggested the possibility that extraverts might also perceive the rates of acoustic and/or visual events to be faster than do introverts. Specifically, they might judge the tone-silence sequences to be faster than the sequences would be judged by introverts.

\section{METHOD}

\section{Participants}

Twenty-two university undergraduates volunteered to participate in the study in order to satisfy a requirement in introductory psychology. Three of the participants were males, and 4 were non-Caucasian. The average age of the participants was 18.9 years, with an $S D$ of 1.3.

\section{Materials}

Stimuli. Two audiotapes were used. The first presented instructions. The second presented the 10 sound-silence sequences that served as the experimental stimuli and were transformations of actual speech samples (monologues) obtained in a previous study (Feldstein \& Sloan, 1984). ${ }^{2}$ The vocalizations of the original speech were converted to 12 $\mathbf{k H z}$ tones with constant intensity, although the pauses of the original speech remained untouched. Each sequence lasted $1 \mathrm{~min}$ and was separated from the following sequence by $25 \mathrm{sec}$.

Scales. Each participant received a four-page booklet. On the first page, the participant provided his or her gender, age, and race, as well as the occupation of his or her parents. The second page provided typed instructions, to be read by the participants as they listened to the identical recorded instructions. On the third page were listed 1010 -point scales, each of which started with " 0 " (very slow) and ended with " 9 " (very fast). The fourth page listed the 25 items of the Extraversion Scale (ES) of the Eysenck Personality Inventory (Eysenck \& Eysenck, 1963). The responses to the items were summed and the sums were positively correlated with degree of extraversion.

\section{Procedure}

The participants came to the Language Center, where they were met and seated by the experimenter and asked to read and sign the consent form if they agreed to participate. The Center contains 60 desks, each one equipped with a headphone connected to an audiocassette recorder/player located in a control unit in the center of the room. Thus all 60 desks can receive the same audio input, with the same acoustical characteristics.

The participants were randomly divided into the two instruction groups, one of which was told that the sound-silence sequences were derived from actual speech (the informed condition), whereas the other was told only that they were to hear sequences of tones and silences (the uninformed condition). Both groups were told that after they heard each sequence, they were to complete the appropriate 10-point scale in order to record their perceptions of the rate of the sequence. A demonstration sequence was played immediately after the instructions to allow the listeners to become familiar with the procedure. It was followed by the second tape, which presented the 10 stimulus sequences. After hearing the 10 sequences and completing the 10 scales, the listeners turned to the last page of the booklet and completed the ES. They were then thanked for their cooperation and given a copy of the signed consent form.

\section{RESULTS}

Two hierarchical multiple regression analyses were used to examine the data in terms of the aims of the study. In the first, the sum of the perceived rates of the 10 tonesilence sequences was the dependent variable. The covariates of gender and race were entered into the equation first. These were followed by the independent variables of instructional conditions and extraversion, and the product of conditions by extraversion (which "carries", the interaction effect). The results are presented in Table 1 . Gender yielded a significant $F$ ratio. However, because only three of the participants were males, the finding was given no further consideration. The only variable of interest that yielded a significant effect was extraversion, indicating that, in general, the extraverts perceived the rates of the sequences to be higher than did the introverts.

In the second regression analysis, the dependent variable was the average perceived rate (over judges) for each of the 10 sequences in each of the two instructional conditions. The first independent variable was instructional conditions and the second was the speech rate, or number of words per minute, per sequence, obtained from the speech sample from which the sequence was derived. The final independent variable was the product of conditions

Table 1

The Relation of Instructional Conditions and Extraversion to the Perceived Rates of Tone-Silence Sequences: A Multiple Regression Analysis

\begin{tabular}{lrrrl}
\hline \multicolumn{1}{c}{ Source } & $d f$ & $M S$ & $R_{i}^{2}$ & \multicolumn{1}{c}{$F$} \\
\hline Gender & 1 & 236.86 & .147 & $4.923^{*}$ \\
Race & 1 & 119.56 & .074 & 2.485 \\
Conditions & 1 & 101.28 & .063 & 2.105 \\
Extraversion & 1 & 377.25 & .235 & $7.841^{*}$ \\
Conditions $\times$ extraversion & 1 & .60 & .000 & .013 \\
Residual & 17 & 48.11 & & \\
\hline
\end{tabular}

Note-The subscript $i$ refers to the incremented proportion of variance. ${ }^{*} p<.05$. 
Table 2

The Relation of Instructional Conditions and Speech Rate to the Average Perceived Rates of the Tone-Silence Sequences: A Multiple Regression Analysis

\begin{tabular}{lrrrc}
\hline \multicolumn{1}{c}{ Source } & $d f$ & $M S$ & $R_{i}^{2}$ & $F$ \\
\hline Conditions & 1 & 1.34 & .066 & 1.714 \\
Speech rate & 1 & 6.40 & .310 & $8.051^{*}$ \\
Conditions $\times$ speech rate & 1 & .15 & .063 & .197 \\
Residual & 16 & .78 & & \\
\hline
\end{tabular}

Note-Speech rate was measured by the number of words per minute of the speech samples from which the tone-silence sequences were derived. ${ }^{*} p<.05$.

by speech rate. Only the relation between speech rate and perceived rate yielded a significant effect (Table 2) such that the higher the perceived rate, the higher was the speech rate of the original speech sample.

\section{DISCUSSION}

The knowledge that the tone-silence sequences were derived from actual speech samples did not appear to influence the perception of their rates. It was hypothesized that this information or the lack of it would generate different expectations about the stimuli. However, the informed listeners did not perceive the rates of the sequences markedly different from the uninformed. ${ }^{3}$

The finding that the perceived rates did not differ as a function of the instructions provides no hint about whether the sequences were differentially processed (in the Liberman \& Mattingly, 1989, sense) by the participants in the two conditions. Specifically, the finding says nothing about whether expectation plays a role in determining how nonspeech stimuli are processed. However, the close relationship of the perceived rates of the sequences to the actual rates (i.e., the words per minute) of the original speech samples suggests that the processing of rate involves a "module" that processes the temporal dimension of events independently of those that attend to other dimensions of speech and nonspeech stimuli. Indeed, such a neurostrategy may function cross-modally; that is, the "module" may process the rate of any behavior in which we engage. One possible mechanism for our finding concerns the frequency distributions of tone and silence durations. We have demonstrated that durations of pauses and vocalizations of speech (as they are defined here) both form a negative exponential distribution, and that the two distributions are statistically orthogonal to each other (see, e.g., Jaffe, Anderson, \& Stern, 1979; Jaffe, Cassotta, \& Feldstein, 1964; Jaffe \& Feldstein, 1970; Jaffe, Feldstein, \& Casssotta, 1967). Inasmuch as the sequences were derived from actual speech, the distributions of their tones and silences remained exponential, and it may be that the shapes of the distributions were sufficient to inform the listener that he or she was hearing speech-that is, to "turn on" the speech "module." This possibility presupposes the existence of either a "neural device" (Lieberman, 1984) that computes or matches the distribution shapes of incoming sequential stimuli, or a cognitive "schema" (Rummelhart \& Ortony, 1977; Taylor \& Crocker, 1979) that develops information about the distributions that characterize various aspects of the speech stream as a function of listeners' repeated experiences with speech. One test of the possibility would involve presenting listeners with sequences in which the tones and silences were not exponentially distributed. ${ }^{4}$ Whatever the explanation, given the relation between the perceived and the actual rates, it appears as if the tone-silence sequences do provide sufficient information for the judging of rate estimates that are generalizable to the original speech samples.

The results also indicate that, in general, the extraverts judged the rates of the tone-silence sequences to be faster than did the introverts. Although this particular finding is at variance with that of a previous study (Crown \& Feldstein, 1991), it raises some interesting questions and possibilities that bear on this issue. First, it suggests that extraverts and introverts differentially process the rates of environmental stimuli. Perhaps the "rate processing module" proposed above is susceptible to the influence of personality characteristics via "internal clocks" that run at different rates. Do extraverts "hear" faster than introverts? Does this differential processing extend to the timing of visual perceptions? ${ }^{5}$ The finding also raises intriguing questions about a possible relationship between the differential rate perception of introverts and extraverts and the differences in their social behavior, such as patience, "coronary-prone" behavior (Feldstein, Siegman, Simpson, Barkley, Kobren, 1984), and so forth.

\section{REFERENCES}

Bond, R. N., Feldstein, S. (1982). Acoustical correlates of the perception of speech rate: An experimental investigation. Joumal of Psycholinguistic Research, 11, 539-557.

Bond, R. N., Feldstein, S., Simpson, S. (1988). Relative and absolute judgments of speech rates from masked and content-standard stimuli: The influence of vocal frequency and intensity. Human Communication Research, 14, 548-567.

Crown, C. L., Feldstein, S. (1991). The perception of speech rate from the sound-silence patterns of monologues. Journal of Psycholinguistic Research, 20, 47-63.

Dohm, F. A., Feldstein, S., Crown, C. L. (1987, April). The perception of speech rate as a function of the perceiver's gender and the speaker's gender. Paper presented at the meeting of the Eastern Psychological Association, Arlington, VA.

Dohm, F. A., Feldstein, S., Crown, C. L. (1988, May). Global speech rate and gender as mediating factors in person perception. Poster presented at the meeting of the Acoustical Society of America, Seattle.

EYSENCK, H. J., EYSENCK, S. B. G. (1963). Manual for the Eysenck Personality Inventory. San Diego: Educational and Industrial Testing Service.

Feldstein, S. (1986, February). The perception of speech rate as a function of the perceived and the perceiver. Paper presented at the 12th Annual Language and Linguistic Symposium, Brigham Young University College of Humanities, Provo, UT.

Feldstein, S., Bond, R. N. (1981). Perception of speech rate as a function of vocal frequency and intensity. Language \& Speech, 24, 385-392.

Feldstein, S., Dohm, F. A., \& Crown, C. L. (1988, November). Rate-dependent perception of interpersonal characteristics. Poster presented at the meeting of the Acoustical Society of America, Honolulu.

Feldstein, S., Siegman, A. W., Barkley, S. E., Simpson, S., * KoBreN, R. (1984, May). Judged and actual speech rates as indices of coronary-prone behavior. Paper presented at the meeting of the Society for Behavioral Medicine, Philadelphia.

Feldstein, S., Siegman, A. W., Simpson, S., Barkley, S. E., \& KoBREN, R. (1984, April). Assessing coronary prone behavior from the temporal structure of speech. Paper presented at the meeting of the Eastern Psychological Association, Baltimore.

Feldstein, S., Slon, B. (1984). Actual and stereotyped speech tempos of extraverts and introverts. Journal of Personality, 52, 188-204.

Grosjean, F. (1977). The perception of rate in spoken and sign languages. Perception \& Psychophysics, 22, 408-413.

Grosjean, F., \& LANE, H. (1974). Effects of two temporal variables on the listener's perceptions of reading rate. Journal of Experimental Psychology, 102, 893-896.

Grosjean, F., Lane, H. (1981). Temporal variables in the perception and production of spoken and sign languages. In P. D. Eimas \& J. L. Miller (Eds.), Perspectives on the study of speech (pp. 207238). Hillsdale, NJ: Erlbaum.

Jaffe, J., Anderson, S. W., \& Stern, D. N. (1979). Conversational rhythms. In D. Aaronson \& R. W. Rieber (Eds.), Psycholinguistic 
research: Implications and applications (pp. 393-434). Hillsdale, NJ: Erlbaum.

JafFe, J., CAssotta, L., \& Feldstein, S. (1964). A Markovian model of time patterns in speech. Science, 144, 884-886.

JAFFe, J., \& Feldstein, S. (1970). Rhythms of dialogue. New York: Academic Press.

JAFFe, J., Feldstein, S., Cassotta, L. (1967). Markovian models of dialogic time patterns. Nature, 216, 93-94.

LANe, H., Grosjean, F. (1973). Perception of reading rate by listeners and speakers. Journal of Experimental Psychology, 97, 141-147.

Liberman, A. M., \& Matringly, I. G. (1989). A specialization for speech perception. Science, 243, 489-494.

Lieberman, P. (1984). The evolution and biology of language. Cambridge, MA: Harvard University Press.

LiPPA, R. (1976). Expressive control and the leakage of dispositional introversion-extraversion during role played teaching. Journal of Personality, 44, 541-559.

MurRay, H. A. (1943). Thematic Apperception Test. Cambridge, MA: Harvard University Press.

Rummelhart, D. E., \& Ortony, A. (1977). The representation of knowledge in memory. In R. C. Anderson, R. J. Spiro, \& W. E. Montague (Eds.), Schooling and the acquisition of knowledge (pp. 99135). Hillsdale, NJ: Erlbaum.

SCHERER, K. R. (1978). Inference rules in personality attribution from voice quality: The loud voice of extraversion. European Journal of Social Psychology, 8, 467-487.

Siegman, A. W. (1987). The telltale voice: Nonverbal messages of verbal communication. In A. W. Siegman \& S. Feldstein (Eds.), Nonverbal behavior and communication (pp. 351-434). Hillsdale, $\mathrm{NJ}$ : Erlbaum.

Simpson, S., Crown, C. L., \& Feldstein, S. (1984, April). The perception of speech rate as a function of the perceiver's speech rate and gender. Paper presented at the meeting of the Eastern Psychological Association, Baltimore.

TAYLOR, S. E., \& CROCKER, J. (1979). Schematic bases of social information processing. In E. T. Higgins, P. Herman, \& M. P. Zanna
(Eds.), The Ontario Symposium on personality and social psychology (Vol. 1, pp. 89-134). Hillsdale, NJ: Erlbaum.

\section{NOTES}

1. This study is part of a series of investigations in which we are concerned with the perception of speech rate and its effects on social evaluation. The series has taken three directions: (1) the influence of the acoustical components of speech on the perception of speech rate (Bond \& Feldstein, 1981; Bond, Feldstein, \& Simpson, 1988; Feldstein \& Bond, 1981); (2) the effects of perceiver characteristics on the perception of speech rate (Dohm, Feldstein, \& Crown, 1987; Feldstein, 1986; Feldstein, Siegman, Barkley, Simpson, \& Kobren, 1984; Simpson, Crown, \& Feldstein, 1984); and (3) the role of speech rate in social evaluation (Crown, 1989; Dohm, Feldstein, \& Crown, 1988; Feldstein, Dohm, \& Crown, 1988). The present study is relevant to the first two directions.

2. The speech samples were spontaneous stories about several pictures of the Thematic Apperception Test (Murray, 1943), a projective instrument that consists of a set of 31 pictures used to elicit stories that are presumed to aid in the assessment of personality characteristics and conflicts.

3. It is possible that to go to the Language Center to participate in the experiment somehow informed the uninformed subjects about the source of the tone-silence sequences and generated the same expectation as that assumed to have been generated by the instructions to the informed subjects. However, the postexperimental remarks of the subjects about the "weirdness" of the sequences, as well as their surprise when they were told about the source of the sequences, made the possibility seem very unlikely.

4. Suggested in a personal communication by Alex Heller, 1968.

5. Anecdotally, Ray Birdwhistell, a charismatic teacher who provided his students and colleagues with delightful bodily illustrations of kinesic behaviors, claimed that he could see many more "frames" per second than could the untrained observer.

(Manuscript received March 11, 1991.) 